ORIGINAL ARTICLE

\title{
An Overview of Analysis of Learning Curve of Laproscopic Procedures in General Surgery Residents in Khyber Teaching Hospital, Peshawar
}

\author{
AHMAD ZARKA ${ }^{1}$, MUSLIHUDDIN ${ }^{2}$, KHALID FURQAN $^{3}$, KHAN SHAHZEB $^{3}$ \\ ${ }^{1}$ Medical Officer Khyber Teaching Hospital, Peshawar \\ ${ }^{2}$ Senior Registrar SCW, Department of Surgery, Khyber Teaching Hospital, Peshawar \\ ${ }^{3}$ Resident SCW, Department of Surgery, Khyber Teaching Hospital, Peshawar \\ ${ }^{3}$ Resident SCW, Department of Surgery, Khyber Teaching Hospital, Peshawar \\ Correspondence to: Ahmad Zarka, Email: zarkaahmad90@gmail.com, Cell: 03469023225
}

\begin{abstract}
ABTRACT
Aim: An Overview of Analysis of Learning Curve of Laparoscopic Procedures in General Surgery Residents in Khyber Teaching Hospital, Peshawar.

Methodology: A descriptive KAP (knowledge attitude and practice) study was conducted in Khyber teaching hospital (KTH) from January 2021 to March 2021. A total of 24 surgical residents of $3^{\text {rd }}$ and $4^{\text {th }}$ year residency working in different surgical units were part of the study. Experience of residents performing procedures under supervision, assistance or by means of observation was recorded by a self administered questionnaire.

Results: A number of 24 surgical residents of $3^{\text {rd }}$ and $4^{\text {th }}$ year residency of general surgery were part of the study. Frequency of $3^{\text {rd }} \mathrm{yr}$ residents was $13(54.2 \%)$ and that of $4^{\text {th }} \mathrm{yr}$ was $11(45.8 \%)$. Number of $6(25 \%)$ observed basic laparoscopy, $8(33 \%)$ advanced procedures and 10(41.7\%) observed both types of procedure. 23(95.8\%) participants were regularly briefed on principles of laparoscopy and $21(87.5 \%)$ strongly agreed upon the need of video simulation sessions. According to $22(91.7 \%)$ participants instrument handling was the most difficult part to learn. And $17(70.8 \%)$ participants laparoscopy enhances visualization of disease process. $18(75 \%)$ participants said that it improves postoperative recovery and 20(83.3\%) were of opinion that it minimizes hospital stay. $16(66.7 \%)$ residents stated it has a steep learning curve. All participants agreed that it is necessary to assist large number of procedures to attain confidence of performing laparoscopic procedures.

Conclusion: The study showed that almost all residents were in favor of the use of laparoscopic procedures rather than open surgeries.

Keywords: Laparoscopy, learning curve
\end{abstract}

\section{INTRODUCTION}

Learning curve concept was first described by T.P. Wright in 1936. According to T.P. Wright, there is direct relation between the efficiency of airplane component production and experience and skill of workforce(1). Learning curve is define as to compare competitive and then evaluate progress and learning target's achievement(2).Surgical management of various pathologies of patients has been revolutionized by laparoscopic surgery(3). Inexperienced clinicians in a procedure are considered to be in an early phase of their learning experience(4) In recent years, the minimally invasive technique has also been used in emergency surgery in an increasing number aswell (5). Most performed general surgical procedures in the world are laparoscopic appendectomy (LA) and laparoscopic cholecystectomy $(\mathrm{LC})(6,7)$. Applied to the operation, the Learning Curve can be defined as the time and / or number of interventions required to perform an intervention with a reasonable result. While learning curve in an open surgery is based on tactile feedback and direct visualization of anatomical structures, these elements are missing in laparoscopy(8). In a 2001 study, Figert found that LC in laparoscopic surgery is essential for the acquisition of laparoscopic skills even for surgeons with experience in open surgery(9). Whether or not the laparoscopic skills necessary to ensure safe intervention can be acquired through learning curve is debatable and numerous studies have attempted to answer this question(10). Learning curve had been focused in many studies to find that after how many surgeries a surgical resident will be able to perform laparoscopic surgeries independently(11). According to the results of these studies, during the learning curve 20 to 30 surgeries should be performed(12). European Association of endoscopic surgeries (EAES) recommended 20 numbers of surgeries for learning curve(13).

Although almost all general surgeons have now acquired the skills to perform laparoscopic procedures, experience with more advanced procedures is quite variable. Several factors hamper the transfer of this technology from specialty centers to mainstream practice. These factors include increased demand for operational suite resources, availability of training, and time commitment to acquire proficiency in these advanced techniques. The aim of this study was to analyze the learning curve of laparoscopic procedures in general surgery residents at Khyber teaching Hospital, Peshawar.

\section{METHODOLOGY}

A descriptive KAP (knowledge attitude and practice) study was conducted in Khyber teaching hospital (KTH) from January 2021 to March 2021. To conduct the study a formal permission was obtained from Hospital Director and Chairman of Department of Surgery, Khyber Teaching Hospital, Peshawar. A total of 24 surgical residents of $3^{\text {rd }}$ and $4^{\text {th }}$ year of residency working in different general surgery units that were present on duty were included in the study while the residents of first- and second-year, residents on rotation to different surgical units, on official 
leave along with those not performing duty in their respective wards were excluded.

During the mentioned time period, experience of the surgical residents performing procedures under supervision, assisting or by means of observation was recorded by a self-administered questionnaire which consisted of questions regarding number the of surgeries observed, assisted and performed under direct supervision by residents, complexity level of surgeries, learning curve, advantages of the laparoscopic surgery compared to open surgery etc were asked. The demographic questions included were year of residency and the working surgical unit.

\section{RESULTS}

The frequency of $3^{\text {rd }}$ year residents was $13(54.2 \%)$ and that of $4^{\text {th }}$ year residents was $11(45.8 \%)$. The frequency of participants working in ward A was $8(33.83 \%)$ in ward $B$ was $6(25.0 \%)$ and ward C was $5(20.8 \%)$, ward D was $2(8.3 \%)$ and ward $E$ was $3(12.5 \%)$.

A total of $7(29.2 \%)$ participants observed less than 20 laparoscopic procedures, $8(23.3 \%)$ observed 20 to 40 procedures, $9(37.5 \%)$ observed more than 40 procedures. Basic laparoscopic procedures were observed by 6 (25.0\%) participants, advanced laparoscopic procedures were observed by $8(33.3 \%)$ participants and both types of procedures were witnessed by $10(41.7 \%)$ participants.

The frequency of participants that were regularly briefed regarding the principles of laparoscopy was $23(95.8 \%)$ while the frequency of participants that were not briefed regarding the principles of laparoscopy was $1(4.2 \%)$. A total of $3(12.5 \%)$ participants agreed upon the need of laparoscopic video and simulating sessions to ease the learning as compared to open surgery while $21(87.5 \%)$ strongly agreed upon the same.

A total of $18(75.0 \%)$ participants have observed less than 10 procedures before assisting first laparoscopic procedure. A number of $4(16.7 \%)$ participants have observed 10 to 20 procedures and $2(8.3 \%)$ have observed more than 20 procedures. The number of participants who have assisted less than 10 procedures were $6(25.0 \%)$, $7(21.16 \%)$ have assisted 10 to 20 procedures and $11(45.83 \%)$ have assisted more than 20 procedures.

The frequency of participants who have worked as first and second assistant was 15(62.5\%), the frequency of participants who have worked as an optical assistant was $3(12.5 \%)$ and the frequency of those participants who have provided both type of assistance was 6(25.0\%). The frequency of participants who find it difficult while creating a pneumoperitoneum and ports placement was 23(95.8\%) and that of participants who find average difficulty was $1(4.2 \%)$. The number of participants who found more complex the principle of triangulation of ports placement from a single procedure specific incision of open surgery was $7(29.2 \%)$, while the frequency of participants who found no difference in both procedures were $8(33.3 \%)$ and $6(25.0 \%)$ found it less complex.

A total of $6(25.0 \%)$ participants said that hand eye coordination was the most challenging part of the learning process of laparoscopy, 18(75.0\%) didn't find it challenging. According to $22(91.7 \%)$ participants instrument handling was the most challenging part while $2(8.3 \%)$ didn't find it challenging. However, $21(87.5 \%)$ participants said range of tactile movement was the most challenging part of the process. A total of 23(97.8\%) said that depth perception was a very challenging component during the entire learning process as given in table 1.

In comparison with open surgery, the frequency of participants who described that laparoscopic procedures are more fatigue causing were $14(58.3 \%), 10(41.7 \%)$ said that it was not a fatigue causing procedure. All participants $24(100 \%)$ agreed upon the statement that it is necessary for a resident to assist large number of laparoscopic procedures to get confident enough to perform the basic procedure under supervision.

According to all residents $24(100 \%)$ laparoscopy is more technical than open surgery. $2(8.3 \%)$ residents said that it is a time consuming process while $22(91.7 \%)$ said that it is not time- consuming. 16(66.7\%) residents said that it has a steep learning curve compared to open surgery. A total of $2(8.3 \%)$ residents said that laparoscopy is more complex than open surgery as evident from table 2 .

According to $17(70.8 \%)$ participants laparoscopy is helpful in improving visualization of disease process. $18(75.0 \%)$ participants said that it helps in minimizing damage to surrounding tissues. $18(75.0 \%)$ participants believed that laparoscopy helps to reduce post-operative pain, nausea and helps in early resumption of activities. $20(83.3 \%)$ participants said that it minimizes the hospital stay. (See table 3 for details)

Table 1: Showing the most challenging part of the learning process

\begin{tabular}{|l|l|l|l|l|}
\hline & Hand-eye coordination & Instrument handling & Tactile movement \\
\hline Yes & $6(25.0 \%)$ & $22(91.7 \%)$ & $21(87.5 \%)$ & Depth perception \\
\hline No & $18(75.0 \%)$ & $2(8.3 \%)$ & $3(12.5 \%)$ & $23(95.83 \%)$ \\
\hline Total & $24(100.0 \%)$ & $24(100.0 \%)$ & $24(100.0 \%)$ & $1(4.2 \%)$ \\
\hline
\end{tabular}

Table 2: Showing the difference from open surgery

Table 2: Showing the difference from open surgery
\begin{tabular}{|l|l|l|l|l|}
\hline & More technical than open surgery & $\begin{array}{l}\text { More time consuming than } \\
\text { open surgery }\end{array}$ & Has steep learning curve & More complex than open surgery \\
\hline Yes & $24(100 \%)$ & $2(8.3 \%)$ & $16(66.7 \%)$ \\
\hline No & $0(0 \%)$ & $22(91.7 \%)$ & $8(33.3 \%)$ & $2(8.3 \%)$ \\
\hline Total & $24(100.0 \%)$ & $24(100.0 \%)$ & $24(100.0 \%)$ & $22(91.7 \%)$ \\
\hline
\end{tabular}

Table 3: Shows improved and optimized outcome of laparoscopic procedures

\begin{tabular}{|c|c|c|c|c|}
\hline & $\begin{array}{l}\text { Improves visualization of disease } \\
\text { process }\end{array}$ & $\begin{array}{l}\text { Minimizing damage to } \\
\text { surrounding tissue }\end{array}$ & $\begin{array}{l}\text { Reduction in post-operative } \\
\text { pain and nausea }\end{array}$ & $\begin{array}{l}\text { Minimizing the duration of hospital } \\
\text { stay }\end{array}$ \\
\hline Yes & $17(70.8 \%)$ & $18(75.0 \%)$ & $18(75.0 \%)$ & $20(83.3 \%)$ \\
\hline No & $7(29.2 \%)$ & $6(25.0 \%)$ & $6(25.0 \%)$ & $4(16.7 \%)$ \\
\hline Total & $24(100.0 \%)$ & $24(100.0 \%)$ & $24(100.0 \%)$ & $24(100.0 \%)$ \\
\hline
\end{tabular}




\section{DISCUSSION}

Countless minimal invasive treatment techniques have been introduced in the medical field that are helpful in improving quality of life, one of them is the increasing trend of laparoscopy. Hence the reason why surgical residents are leaning towards performing laparoscopic procedures rather than open surgeries.(11)

The current study identified the learning curve of laparoscopic procedures in general surgery residents. The study recruited a total number of 24 participants who were residents of $3^{\text {rd }}$ and $4^{\text {th }} y r$ surgical training program. The results of the study showed that most participants agreed upon the use of laparoscopy rather than open surgery through- out their learning process.

The study of Rezola et al also showed similar results in which the questions were asked about the good results of laparoscopic procedure from the surgical residents and all agreed upon the better results of it as same in the current study in which during the learning process of trainees laparoscopic procedures were effective in reducing post-operative pain and nausea .(14)

Another study conducted by B.Kreistein et al showed in his study that post-operative complications were reduced following laparoscopy done by surgical residents for abdominal emergencies as same in the current study in which post-operative complications were reduced as described by surgical residents further the residents recommend this non-invasive procedure through their learning process rather than open surgeries. (5)

Another study conducted by WP Geis et al that laparoscopic procedure was helpful in visualization of internal abdominal cavity and pathology as similar in the current study in which surgical residents highlighted that this procedure was helpful in visualization of diseased process.(15)

Epaminondas et al showed in his study that learning curve is having a potential relationship between learning effort and outcome. The usual method of learning is by active learning and feedback. Where-as steep learning curve is rapid learning which is easy to learn and implement.(16)

\section{CONCLUSION}

The current study enlightens the view of surgical residents on the use of laparoscopic procedures. The study showed that almost all residents were in favor of the use of laparoscopic procedures rather than open surgeries.

Conflict of Interest: The author didn't find any conflict of interest regarding the current study.

\section{REFERENCES}

1. Esposito C, Hollands C, Lima M, Settimi A, Valla J-S. Videochirurgia pediatrica: Principi di tecnica in laparoscopia, toracoscopia e retroperitoneoscopia pediatrica: Springer Science \& Business Media; 2011.

2. Dar-El EM, Rubinovitz J. Using learning theory in assembly lines for new products. International Journal of Production Economics. 1991;25(1-3):103-9.

3. McCoy AC, Gasevic E, Szlabick RE, Sahmoun AE, Sticca RP. Are open abdominal procedures a thing of the past? An analysis of graduating general surgery residents' case logs from 2000 to 2011. Journal of surgical education. 2013;70(6):683-9.

4. Hopper AN, Jamison MH, Lewis WG. Learning curves in surgical practice. Postgraduate medical journal. 2007;83(986):777-9.

5. Kirshtein B, Roy-Shapira A, Lantsberg L, Mandel S, Avinoach E, Mizrahi S. The use of laparoscopy in abdominal emergencies. Surgical Endoscopy And Other Interventional Techniques. 2003;17(7):1118-24.

6. Shabtai M, Rosin D, Zmora O, Munz Y, Scarlat A, Shabtai E, et al. The impact of a resident's seniority on operative time and length of hospital stay for laparoscopic appendectomy: outcomes used to measure the resident's laparoscopic skills. Surgical Endoscopy And Other Interventional Techniques. 2004;18(9):1328-30.

7. Watanabe Y, Bilgic E, Lebedeva E, McKendy KM, Feldman LS, Fried GM, et al. A systematic review of performance assessment tools for laparoscopic cholecystectomy. Surgical endoscopy. 2016;30(3):832-44.

8. Kumar U, Gill IS. Learning curve in human laparoscopic surgery. Current urology reports. 2006;7(2):120-4.

9. Figert PL, Park AE, Witzke DB, Schwartz RW. Transfer of training in acquiring laparoscopic skills. Journal of the American College of Surgeons. 2001;193(5):533-7.

10. Grantcharov TP, Bardram L, Funch-Jensen P, Rosenberg J. Assessment of technical surgical skills. The European journal of surgery. 2002;168(3):139-44.

11. Kim SY, Hong SG, Roh HR, Park SB, Kim YH, Chae GB. Learning curve for a laparoscopic appendectomy by a surgical trainee. Journal of the Korean Society of Coloproctology. 2010;26(5):324.

12. Jaffer U, Cameron AE. Laparoscopic appendectomy: a junior trainee's learning curve. JSLS: Journal of the Society of Laparoendoscopic Surgeons. 2008;12(3):288.

13. Neugebauer E, Troidl H, Kum C, Eypasch E, Miserez M, Paul A. The EAES Consensus Development Conferences on laparoscopic cholecystectomy, appendectomy, and hernia repair. Surgical endoscopy. 1995;9(5):550-63.

14. Rezola E, Villanueva A, Garay J, Sunol M, Arana J, Intxaurrondo $\mathrm{M}$, et al. Laparoscopic appendectomy after the learning curve. Cirugia pediatrica: organo oficial de la Sociedad Espanola de Cirugia Pediatrica. 2008;21(3):16772.

15. Geis W, Kim H. Use of laparoscopy in the diagnosis and treatment of patients with surgical abdominal sepsis. Surgical endoscopy. 1995;9(2):178-82.

16. Valsamis EM, Chouari T, O'Dowd-Booth C, Rogers B, Ricketts $D$. Learning curves in surgery: variables, analysis and applications. Postgraduate medical journal. 2018;94(1115):525-30. 